This item was submitted to Loughborough's Research Repository by the author.

Items in Figshare are protected by copyright, with all rights reserved, unless otherwise indicated.

\title{
Analytical analysis and optimisation of the Rayleigh step slider bearing
}

PLEASE CITE THE PUBLISHED VERSION

http://dx.doi.org/10.1016/j.triboint.2008.09.002

PUBLISHER

(c) Elsevier

VERSION

AM (Accepted Manuscript)

LICENCE

CC BY-NC-ND 4.0

REPOSITORY RECORD

Rahmani, Ramin, Ayoub Shirvani, and Hassan Shirvani. 2019. "Analytical Analysis and Optimisation of the Rayleigh Step Slider Bearing”. figshare. https://hdl.handle.net/2134/12899. 
This item was submitted to Loughborough's Institutional Repository (https://dspace.lboro.ac.uk/) by the author and is made available under the following Creative Commons Licence conditions.

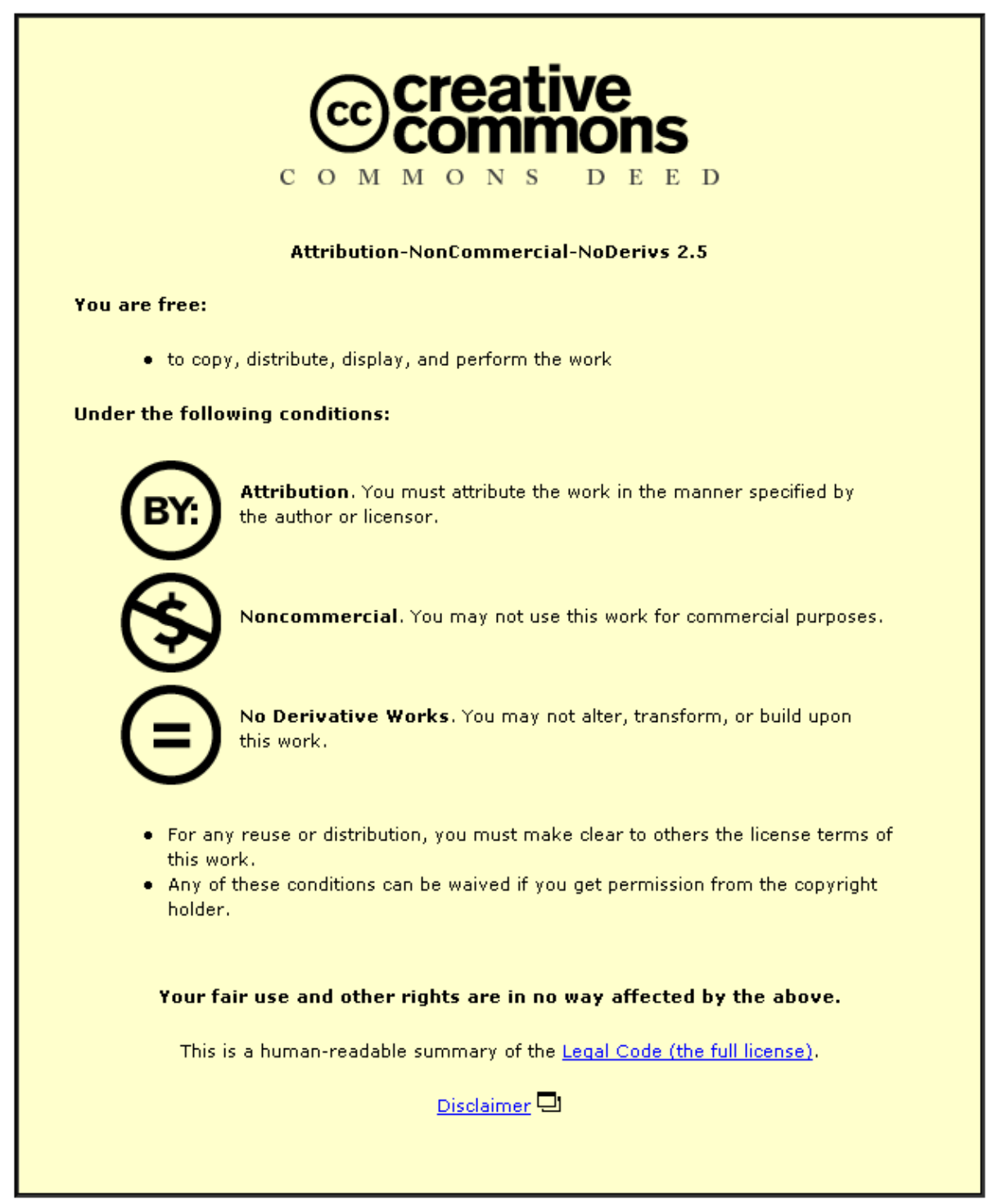

For the full text of this licence, please go to: http://creativecommons.org/licenses/by-nc-nd/2.5/ 
Tribology International, 2009, Vol. 42, No. 5, pp. 666-674

(Accepted Version)

\title{
Analytical Analysis and Optimisation of the Rayleigh Step Slider Bearing
}

\author{
R. Rahmani ${ }^{1}$, A. Shirvani ${ }^{2}$, H. Shirvani ${ }^{3}$ \\ Faculty of Science and Technology, Anglia Ruskin University \\ Victoria Road South, Chelmsford, Essex CM1 1LL, UK \\ Phone: +44 (1245) 493131; Fax: +44 (1245) 493136 \\ Email: ramin.rahmani@anglia.ac.uk
}

\begin{abstract}
In tribology, the Rayleigh step is known as a bearing with the highest load capacity amongst all other possible bearing geometries. In classical resources on tribology, it is also shown that there is an optimum geometry for the Rayleigh step providing the highest load capacity. However, the analyses are confined to a special case where the effect of hydrostatic pressure is neglected. Furthermore, the possible optimum parameters in terms of the friction force and/or friction coefficient as well as the lubricant flow rate have not been discussed. In this study, the Rayleigh step is comprehensively analysed including the effect of variations of pressure at the boundaries on the optimum parameters. In addition, the bearing is also optimised considering lubricant flow rate, friction force and friction coefficient. It is shown that the optimum bearing parameters are strictly dependent on the variations of the pressure at the boundaries. It is also verified that the optimum point(s) in terms of load capacity are not necessarily equal to the optimum point(s) considering friction coefficient and/or lubricant flow rate even though if there is no pressure difference between bearing endings.
\end{abstract}

Keywords: Rayleigh step; optimisation; load capacity; friction coefficient; lubricant flow rate

\section{Introduction}

In 1918, Lord Rayleigh discovered a method of introducing a fixed variation in the lubricant film thickness without the use of tilting [1]. In fact, he used the calculus of variations to see which film shape (for the infinite bearing) had the largest load carrying capacity. He discovered that the best form was two parallel zones [2]. In this bearing, there are two surfaces, one parallel to the other (bottom) surface, which divides the lubricant film into two zones. His result is true also for the viscosity of the more general case when the viscosity of lubricant is considered as a function of pressure [3]. Since then, there have been some studies on the characteristics of this bearing. Archibald [4] considered a stepped slider with finite width to calculate the side-leakage effect on the bearing tribological properties. He found that when side leakage is considered, the optimal step shape changed considerably from that obtained by Rayleigh, and the load capacity was lower. In his later work, Archibald [5] extended the analysing of Rayleigh step bearing where it was used in the journal bearings. He resulted in an optimal film thickness ratio of 1.68. Hamrock and Andersson [6] studied the pressure distribution, load

\footnotetext{
${ }^{1} \mathrm{PhD}$ Student, Correspondent Author

${ }^{2}$ Senior Research Fellow

${ }^{3}$ Professor of Engineering Design and Simulation
} 
Tribology International, 2009, Vol. 42, No. 5, pp. 666-674

(Accepted Version)

capacity, load angle and friction force theoretically, for a single-step concentric Rayleigh step journal bearing (see also [7]) and for an eccentric Rayleigh step journal bearing with varying numbers of steps and infinite length Rayleigh step journal bearing (see also [8]). In the both of cases, they have reported an optimal film thickness ratio of 1.7. In addition, their results indicated that a single step placed around the journal was optimal. The previous analytical results encouraged Schuller [9] to investigate the stability of the Rayleigh step hydrodynamic journal bearings in four different configurations with low viscosity lubricants at zero loads, experimentally. Auloge et al [10], and Jianming and Gaobing [11] have presented the optimum design of one-dimensional Rayleigh step bearing with non-Newtonian lubricants. Tello [12] has theoretically studied the regularity of the solution to the Reynolds equation in Rayleigh step type bearings for both compressible and incompressible fluids by employing a rigorous mathematical approach. Zhu [13] has investigated both numerically and experimentally the response of a rotor supported on Rayleigh step gas bearing using Galerkin finite element method. Thermohydrodynamic lubrication (THL) analysis method has also been applied to the study of (Rayleigh) step bearing by Hideki [14]. Using singular perturbation method, Farmer and Shepherd [15] have analysed the isothermal operation of the Rayleigh step bearing, considering rarefied gas lubrication and thus slip flow condition. The influence of step geometry and degree of slip on the pressure field and bearing performance has been discussed in details in [15]. In a most recent work, Naduvinamani and Siddangouda [16] have also studied the effect of surface roughness on the hydrodynamic lubrication of porous step-slider bearings with couple stress fluids theoretically.

Rayleigh step bearings have been of interest in industry from shaft-bearing systems such as (high-speed) turbomachinery to microelectromechanical systems (MEMS) as well as the computer industry in devices such as magnetic head recording or hard/floppy disc drives [12-14]. Their higher load capacity and cheap/easy manufacturing has made them more favourable to be used especially in situations wherever the air or gases are used as a lubricant in which because of their lower viscosity application of a hybrid hydrostatic/hydrodynamic mode is inevitable. Because of these advantages, the Rayleigh step profile is still used in thrust and pad bearings. In addition, in journal bearings a series of Rayleigh steps are used to form a grooved bearing with higher performance [1].

In classical literature on tribology, using a relatively simple calculation, it is usually shown that based on the load capacity it is possible to introduce an optimum geometry for the Rayleigh step bearing (e.g. [1-3, 17]). For example, Pinkus and Strenlicht [3] have shown that the optimum height and length ratio for the Rayleigh step when the pressure difference between two ends of bearing is zero - are 1.866 and 2.549 respectively and the same optimum point is suggested in other resources as well.

In this study, the infinite width Rayleigh step slider bearing is analysed analytically based on the Reynolds hydrodynamic lubrication equation considering the existence of hydrostatic pressure difference between the bearing ends; the situation likely happen in practice as well. For this purpose, the $1 \mathrm{D} / 2 \mathrm{D}$ form of the Reynolds equation is solved analytically for the Rayleigh step bearing using direct integration method. Then, a suitable form of the analytical relations for the desired parameters such as load capacity, friction force, etc. have been developed and subjected to a rather extensive optimum seeking examinations. 
Tribology International, 2009, Vol. 42, No. 5, pp. 666-674

(Accepted Version)

\section{Problem Formulization}

The 1D/2D form of steady Reynolds equation for an incompressible lubricant with constant viscosity can be expressed in the following form (see Figure 1) [3]:

$$
\frac{\partial}{\partial x}\left(h^{3}(x) \frac{\partial p(x)}{\partial x}\right)=6 \mu U_{1} \frac{\partial h(x)}{\partial x}
$$

Double integrating of this equation with respect to $x$, will result in the pressure distribution along the bearing surface as below:

$$
p(x)=6 \mu U_{1} \int_{a}^{c} \frac{1}{h(x)^{2}} d x+c_{1} \int_{a}^{c} \frac{1}{h(x)^{3}} d x+c_{2}
$$

in which $a$ and $c$ are the coordinates of the bearing leading and trailing ends (see Figure 1) and $c_{1}$ and $c_{2}$ are integration constants, which can be found from boundary condition. The boundary conditions for pressure may be expressed as below:

$$
\left\{\begin{array}{l}
\left.p\right|_{x=a}=0 \\
\left.p\right|_{x=c}=P_{c}-P_{a}
\end{array}\right.
$$

Employing these boundary conditions, the integration constants would be determined as follows:

$$
\left\{\begin{array}{l}
c_{1}=\frac{\left(P_{c}-P_{a}\right)-6 \mu U_{1} \int_{a}^{c} \frac{1}{h(x)^{2}} d x}{\int_{a}^{c} \frac{1}{h(x)^{3}} d x} \\
c_{2}=0
\end{array}\right.
$$

The surface profile for a given Rayleigh step (see Figure 1) can be defined as:

$$
h(x)= \begin{cases}h_{1} ; & a \leq x<b \\ h_{2} ; & b \leq x \leq c\end{cases}
$$

Using this surface profile, the pressure distribution for the first and second 'zones' or 'regions' of the bearing (specified by I and II in Figure 1) can be expressed respectively in the following forms:

$$
\left\{\begin{array}{l}
\left.p(x)\right|_{x \in[a, b]}=6 \mu U_{1} \frac{(x-a)}{h_{1}{ }^{2}}+c_{1} \frac{(x-a)}{h_{1}{ }^{3}} \\
\left.p(x)\right|_{x \in] b, c]}=6 \mu U_{1}\left[\frac{l_{1}}{h_{1}{ }^{2}}+\frac{(x-b)}{h_{2}{ }^{2}}\right]+c_{1}\left[\frac{l_{1}}{h_{1}{ }^{3}}+\frac{(x-b)}{h_{2}{ }^{3}}\right]
\end{array}\right.
$$

In addition, the integration constant $c_{1}$ can be determined as follows:

$$
c_{1}=\frac{\left(P_{c}-P_{a}\right)-6 \mu U_{1}\left(\frac{l_{1}}{h_{1}^{2}}+\frac{l_{2}}{h_{2}{ }^{2}}\right)}{\frac{l_{1}}{h_{1}^{3}}+\frac{l_{2}}{h_{2}{ }^{3}}}
$$


Tribology International, 2009, Vol. 42, No. 5, pp. 666-674

(Accepted Version)

Having the pressure distribution, the load capacity of the bearing ${ }^{4}$ is calculated using the pressure distribution as below:

$$
W=\int_{a}^{c} p(x) d x=3 \mu U_{1}\left[\frac{l_{1}\left(l_{1}+2 l_{2}\right)}{h_{1}{ }^{2}}+\frac{l_{2}{ }^{2}}{h_{2}{ }^{2}}\right]+\frac{c_{1}}{2}\left[\frac{l_{1}\left(l_{1}+2 l_{2}\right)}{h_{1}{ }^{3}}+\frac{l_{2}{ }^{2}}{h_{2}{ }^{3}}\right]
$$

In order to introduce the associated relation for friction force, the velocity profile inside the lubricant film is considered as below [3]:

$$
u(x, y)=\frac{1}{2 \mu} \frac{\partial p(x)}{\partial x}\left(y^{2}-h(x) y\right)+U_{1}\left(\frac{h(x)-y}{h(x)}\right)
$$

The wall shear stress for the lower surface is defined as below:

$$
\tau(x)=\left.\mu \frac{\partial u(x, y)}{\partial y}\right|_{y=0}
$$

Replacing the velocity profile from (9) and the pressure gradient - which is calculated from (6) - would result in the wall shear stress for the lower surface as below:

$$
\tau(x)=-\left(4 \mu U_{1} \frac{1}{h(x)}+c_{1} \frac{1}{2 h(x)^{2}}\right)
$$

Using the wall shear stress from (11) and integrating over the entire bearing length, the friction force for the lower surface can be stated as below:

$$
F=\int_{a}^{c} \tau(x) d x=-\left\{4 \mu U_{1}\left(\frac{l_{1}}{h_{1}}+\frac{l_{2}}{h_{2}}\right)+\frac{c_{1}}{2}\left(\frac{l_{1}}{h_{1}{ }^{2}}+\frac{l_{2}}{h_{2}{ }^{2}}\right)\right\}
$$

Now, the friction coefficient for the lower surface can be defined as follows:

$$
\eta=\frac{F}{W}
$$

in which $F$ and $W$ are replaced from (12) and (8) respectively.

Finally, the volume flow rate of the lubricant can be calculated from the following relation [3]:

$$
q=-\frac{1}{12 \mu}\left(\frac{\partial p}{\partial x}\right)_{I} h_{1}^{3}+\frac{1}{2} U_{1} h_{1}
$$

if the pressure gradient is calculated from the first pressure distribution relation given in equation (6) that is for the region I in Figure 1. Correspondingly, if the pressure gradient is calculated for the region II, then $h_{1}$ must be replaced with $h_{2}$ in equation (14).

The 'base length ratio, $\varepsilon$, and the '(step) height ratio', $\xi$, are defined for the bearing as follows respectively:

$$
\varepsilon=\frac{l_{1}}{L} ; \quad(0<\varepsilon<1)
$$

and

$$
\xi=\frac{h_{2}}{h_{1}} ; \quad(\xi>1)
$$

\footnotetext{
${ }^{4}$ Note that since the analyses are confined to 1D/2D form, the load capacity and friction force are per unit width.
} 
Tribology International, 2009, Vol. 42, No. 5, pp. 666-674

(Accepted Version)

Using these notions, and considering $U_{1}=-U(U>0)$, the equations (8), (12) and (14) for the load capacity, friction force and lubricant flow rate can be recast in the following form:

$$
\begin{gathered}
\Lambda_{W}=3\left[\frac{\varepsilon(1-\varepsilon)(\xi-1)}{\varepsilon\left(\xi^{3}-1\right)+1}\right]+\left(\frac{\Lambda}{2}\right)\left[\frac{\varepsilon(2-\varepsilon)\left(\xi^{3}-1\right)+1}{\varepsilon\left(\xi^{3}-1\right)+1}\right] \\
\Lambda_{F}=\left[\frac{(\xi-1)^{4} \varepsilon^{2}+2(\xi-1)\left(2 \xi^{2}-\xi+1\right) \varepsilon+1}{\xi\left[\varepsilon\left(\xi^{3}-1\right)+1\right]}\right]-\left(\frac{\Lambda}{2}\right)\left[\xi \frac{\varepsilon\left(\xi^{2}-1\right)+1}{\varepsilon\left(\xi^{3}-1\right)+1}\right]
\end{gathered}
$$

and

$$
\Lambda_{q}=\frac{\xi\left[6\left(\varepsilon \xi^{2}+1-\varepsilon\right)-\Lambda \xi^{2}\right]}{12\left(\varepsilon \xi^{3}+1-\varepsilon\right)}
$$

respectively, in which $\Lambda, \Lambda_{\mathrm{W}}, \Lambda_{\mathrm{F}}$ and $\Lambda_{\mathrm{q}}$ are:

$$
\Lambda=\frac{\left(P_{c}-P_{a}\right) h_{1}^{2}}{\mu U L}, \Lambda_{W}=\frac{W h_{1}^{2}}{\mu U L^{2}}, \Lambda_{F}=\frac{F h_{1}}{\mu U L} \text { and } \Lambda_{q}=\frac{q}{U h_{1}}
$$

and can be considered as 'modified bearing number', dimensionless load capacity, dimensionless friction force and dimensionless volume flow rate of lubricant respectively.

The friction coefficient on the lower surface also would be:

$$
\eta=\frac{|F|}{W}=\left(\frac{\left|\Lambda_{F}\right|}{\Lambda_{W}}\right) \cdot\left(\frac{h_{1}}{L}\right)
$$

Based on equation (21), the modified friction coefficient can be defined as:

$$
\eta_{M}=\eta\left(\frac{L}{h_{1}}\right)
$$

It is noted that for simplicity, the term 'dimensionless' would be dropped down before load capacity, friction force and volume flow rate of lubricant in the rest of this article. It is so for the term 'modified' before the bearing number and friction coefficient as well as the terms 'step' before the height ratio.

\section{Optimisation Results and Discussion}

In this section, the resulted relations above will be examined in order to find the possible optimum parameters or combinations of them, which will provide the maximum load capacity, or minimum friction force or friction coefficient as well as minimum lubricant flow rate in different conditions.

\subsection{The load capacity}

Based on the pressure difference between leading and trailing edges of the bearing, the load capacity can mathematically be positive or negative. However, the maximum positive load capacity would be of interest. Solving the equation $\Lambda_{\mathrm{W}}=0$ for modified bearing number and determining the limitations of variations of $\Lambda$ based on $\varepsilon$ and $\xi$ shows that for $\Lambda<-0.295$, the load capacity is always negative. For $\Lambda$ in the range between -0.295 and 0 (including $\Lambda=0$ ), the load capacity can be negative or positive dependent to the $\varepsilon$ and $\xi$ in which the maximum load capacity would be apparently 
Tribology International, 2009, Vol. 42, No. 5, pp. 666-674

(Accepted Version)

positive. Finally, for $\Lambda>0$ the load capacity is always positive. Therefore, the lower limit of the variations of $\Lambda$ - whenever load capacity is involved - would be -0.295.

From equation (17), it can be seen that the load capacity would increase linearly with $\Lambda$; making it impossible to determine a specific optimum modified bearing number that makes the load capacity maximum. However, the probable optimum $\varepsilon$ and/or $\xi$, which make $\Lambda_{\mathrm{W}}$ maximum, can be a function of modified bearing number.

By differentiating modified load capacity from equation (17) with respect to height and base length ratios and examining the second derivatives, it results that the optimum height and/or base length ratios can be attained by solving the set of equations below,

$$
\left\{\begin{array}{l}
\left(\varepsilon_{\text {opt }}\right)_{W}=\frac{\xi \sqrt{\xi}-1}{\xi^{3}-1} \\
\left(\xi_{\text {opt }}\right)_{W}=\frac{1}{12 \varepsilon}\left[\left(A_{1}+12 \varepsilon \sqrt{6(1-\varepsilon) A_{2}}\right)^{1 / 3}+(\Lambda+6 \varepsilon)^{2}\left(A_{1}+12 \varepsilon \sqrt{6(1-\varepsilon) A_{2}}\right)^{-1 / 3}+(\Lambda+6 \varepsilon)\right]
\end{array}\right.
$$

in which

$$
\begin{aligned}
& A_{1}=(\Lambda+6 \varepsilon)^{3}+432 \varepsilon^{2}(1-\varepsilon) \\
& A_{2}=(\Lambda+6 \varepsilon)^{3}+216 \varepsilon^{2}(1-\varepsilon)
\end{aligned}
$$

Apparently, in the case of having more than one set of answers, which might happen for some $\Lambda$ - more likely representing the local minimum point(s) - the results should be re-examined to determine the optimum set providing highest load capacity for the given $\Lambda$. As can be observed from equation (23), the optimum base length ratio is a function of height ratio solely and for any given $\xi$ provides the correspondent base length ratio which supplies the maximum load capacity regardless of the value of $\Lambda$. Figure 2 shows the variations of maximum $\Lambda_{\mathrm{W}}$ based on $\varepsilon$ with height ratio for different modified bearing numbers. As it can be seen from this figure for $-0.295<\Lambda<1.095$, it is possible to introduce a unique set of optimum length and height ratios which provides the highest load capacity for any given $\Lambda$ in this range. For $\Lambda \approx 1.095$, the maximum $\Lambda_{\mathrm{W}}$ based on $\varepsilon$, increases with $\xi$ for $\xi<6.129$ and after this point it remains constant. For $\Lambda>1.095$, there is not any specific optimum height ratio and the maximum $\Lambda_{\mathrm{W}}$ based on $\varepsilon$ increases uniformly with the height ratio. In addition, it can be seen that for all possible range of variations of the height ratio the optimum base length ratio would only vary from 0.5 to 0 .

\subsection{The friction force}

Based on equation (12) and the dimensionless form of it in (18), one may seek for situation(s) in which $\Lambda_{\mathrm{F}}=0$. Solving of the equation $\Lambda_{\mathrm{F}}=0$ for modified bearing number and determining the limitations of variations of $\Lambda$ based on $\varepsilon$ and $\xi$ shows that for $0<\Lambda<2$, there is a pair of height and length ratios, making the net friction force on the lower surface zero. By solving $\Lambda_{\mathrm{F}}=0$ for the base length ratio, it is possible to introduce the base length ratio(s) that makes the net friction force to be zero for any given height ratio and $\Lambda$ in a specified range as follow:

$$
\left(\varepsilon_{\text {opt }}\right)_{F}=\frac{\Lambda \xi^{3}+(\Lambda-8) \xi^{2}+4(\xi-1)+\xi\left[(\xi+1)^{2}(\xi \Lambda-8)^{2}+32 \xi(\xi \Lambda-6)\right]^{1 / 2}}{4(\xi-1)^{3}}
$$

in which 
Tribology International, 2009, Vol. 42, No. 5, pp. 666-674

(Accepted Version)

$$
\xi \geq\left(\frac{2}{\Lambda}\right)^{1 / 2} \text { and }(0<\Lambda<2)
$$

are the prerequisites to have $0<\varepsilon<1$. Therefore, in these ranges there is a wide variety of options to have the minimum possible friction force.

On the other hand, examining equation (18) for $\Lambda<0$ and $\Lambda>2$ shows that the net friction force is always positive and negative respectively for all values of base length and height ratios. To find the minimum absolute value of friction force in these ranges, calculating the first differentiation of $\Lambda_{\mathrm{F}}$ in equation (18) with respect to $\varepsilon$ and examining of the second correspondent derivative for resulted $\varepsilon$ shows that in the range of $\Lambda<0$ it is possible to introduce a minimum friction force for any given height ratio considering some limitations:

$$
\left(\varepsilon_{\text {opt }}\right)_{F}=\frac{2(1-\xi)+\xi^{2}\left\{-2\left[6+\Lambda\left(\xi^{2}+\xi+1\right)\right]\right\}^{1 / 2}}{\left(\xi^{2}+\xi+1\right)(\xi-1)^{2}}
$$

in which

$$
-2\left(\xi^{2}+3 \xi-3\right)<\Lambda<-2\left(\frac{3 \xi^{2}-3 \xi+1}{\xi^{4}}\right)
$$

The resulting friction force, which would be a function of height ratio for any given modified bearing number, will reduce by increasing the height ratio so that if $\xi \rightarrow \infty,{ }^{5}$ then $\left(\Lambda_{\mathrm{F}}\right)_{\min }=-\Lambda / 2$.

If the condition in (25-1) does not hold and $\Lambda<-2$, the minimum friction force would happen when $\varepsilon \rightarrow 1$ for any given $\xi$ resulting in $\left(\Lambda_{\mathrm{F}}\right)_{\min }=1-\Lambda / 2$. However, if $2<\Lambda<0$, the minimum friction force would happen when $\varepsilon \rightarrow 0$ and $\xi=(2 /|\Lambda|)^{1 / 2}$ resulting in $\left(\Lambda_{\mathrm{F}}\right)_{\min }=(2 \Lambda)^{1 / 2}$. For $\Lambda>2$, there is not any stationary point for friction force based on the base length ratio and the friction force reduces with increasing of the base length ratio resulting minimum friction force $\left(\Lambda_{\mathrm{F}}\right)_{\min }=1-\Lambda / 2$ based on the base length ratio when $\varepsilon \rightarrow 1$.

Applying the same procedure for the height ratio indicates that in the range of $\Lambda<-$ 2 , for any given base length ratio and $\Lambda$, the relation below

$$
\xi=\frac{\left[(2-\varepsilon+2 \sqrt{1-\varepsilon}) \varepsilon^{2}\right]^{1 / 3}}{2 \varepsilon}+\frac{\varepsilon}{2\left[(2-\varepsilon+2 \sqrt{1-\varepsilon}) \varepsilon^{2}\right]^{1 / 3}}+\frac{1}{2}
$$

indicates the locus of global maximum for friction force. However, for the range of $2<\Lambda<0$ equation (27) reveals the locus of local maximum point for any given base length ratio. For $\Lambda>2$, equation (26) represents locus of local maximum for absolute value of friction force. In addition, the height ratios providing local minimum friction force for any given base length ratio and modified bearing numbers in the ranges of $-2<\Lambda<0$ and $\Lambda>2$ are as follow,

$$
\xi=\frac{1}{12 \varepsilon}\left[\left(A_{1}+12 \varepsilon \sqrt{6(1-\varepsilon) A_{2}}\right)^{1 / 3}+(\Lambda+6 \varepsilon)^{2}\left(A_{1}+12 \varepsilon \sqrt{6(1-\varepsilon) A_{2}}\right)^{-1 / 3}+(\Lambda+6 \varepsilon)\right]
$$

\footnotetext{
${ }^{5}$ Here it should be noted that since the analyses in this study are based on the Reynolds lubrication equation, the following limitation on the height ratio should be implemented to make sure that the analyses are not violating the essential assumptions made to derive the Reynolds equation:

$$
\left(\frac{\xi}{1-\varepsilon}\right) \frac{h_{1}}{L} \leq O\left(10^{-3}\right)
$$
}


Tribology International, 2009, Vol. 42, No. 5, pp. 666-674

(Accepted Version)

in which

$$
\text { for }(\Lambda \neq-6 \varepsilon,-2<\Lambda<0 \text { or } \Lambda>2)
$$

$$
\begin{aligned}
& A_{1}=(\Lambda+6 \varepsilon)^{3}+432 \varepsilon^{2}(1-\varepsilon) \\
& A_{2}=(\Lambda+6 \varepsilon)^{3}+216 \varepsilon^{2}(1-\varepsilon)
\end{aligned}
$$

Generally, the global minimum for friction force based on the height ratio for any given base length ratio and $\Lambda<0$ happens if $\xi \rightarrow \infty$. In this case, the minimum friction force will be $\left(\Lambda_{\mathrm{F}}\right)_{\min }=\varepsilon-\Lambda / 2$. On the other hand, for $\Lambda>2$, the global minimum for absolute value of friction force happens if $\xi \rightarrow 1$. In this case, the minimum friction force will be $\left(\Lambda_{\mathrm{F}}\right)_{\min }=|1-\Lambda / 2|$. Moreover, in this range, if $\xi \rightarrow \infty$, the absolute value of the friction force would be the maximum for any given base length ratio and $\Lambda$.

Equations (26) and (27) also represent the locus of local maximum and minimum points for friction force in the range of $0<\Lambda<2$. In this case, if the resulted height ratios are less than the height ratio that provides zero friction force, then the resulted height ratio from equation (26) would represent the locus of local minimum point and the resulted height ratio from equation (27) would represent the locus of local maximum point. If the resulted height ratios are greater than the height ratio that provides zero friction force, then the trend is reversed. Figure 3 shows the variation of friction force with height ratio for some different $\Lambda$ when $\varepsilon=0.35$. It should be noted that the results in Figure 3 are scaled between 0 and 1 for better representation. As it can be seen from this figure, for $\Lambda \leq 0$ and $\Lambda \geq 2$ the minimum friction force happens when $\xi \rightarrow \infty$ and $\xi \rightarrow 1$ respectively.

In general, the direction of friction force on the bearing surface(s) can be variable dependent to $\Lambda, \varepsilon$ and $\xi$. In some cases, it is possible that the direction of friction force on the bearing surfaces (e.g. lower surface) changes before and after the step (regions I and II in Figure 1). This happens when the lubricant velocity originated from the pressure difference becomes greater than the velocity of moving bearing surface (naturally in the stepped region). Therefore, if the magnitude of these local friction forces in the opposite directions becomes equal, as an outcome the bearing surface would experience no net resultant friction force based on equation (12) or consequently equation (18). In fact, the given discussion on the optimisation of the friction force above is based on minimisation of net force exerted on the bearing surface(s) by means of shear. As Archibald [4] states, in the former case, the required force to move the surface is calculated and hence it might have been more suitable to use the term 'exerted moving force on the surface" instead of friction force. This is because considering the entropy generation associated to the shear between lubricant and bearing surface, even in the cases in which the net friction force is zero, there is 'entropy generation' considering absolute value of local shear stresses in non-stepped and stepped regions of the bearing (specified by I and II in Figure 1). The mechanism is similar to that of a cable being pulled by two equal forces in the opposite directions. In this case, although the cable would not move towards either of sides, the entropy of the 'system' will increase. Therefore, minimising the friction force based on the ‘entropy generation' concept needs to consider the sum of absolute values of local friction forces in regions I and II in Figure 1, i.e.:

$$
\Lambda_{F}^{\prime}=\left|\left(\Lambda_{F}\right)_{I}\right|+\left|\left(\Lambda_{F}\right)_{I I}\right|
$$


Tribology International, 2009, Vol. 42, No. 5, pp. 666-674

(Accepted Version)

in which the first term in the right hand side is the friction force associated to the region I and the second term in the right hand side is the friction force associated to the region II (stepped region). These parameters are given as below:

$$
\begin{aligned}
\left(\Lambda_{F}\right)_{I} & =\frac{\varepsilon\left[(2 \varepsilon-\Lambda) \xi^{3}+2(1-\varepsilon)(4-3 \xi)\right]}{2\left[\varepsilon\left(\xi^{3}-1\right)+1\right]} \\
\left(\Lambda_{F}\right)_{I I} & =\frac{(1-\varepsilon)\left[8 \varepsilon \xi^{3}-(\Lambda+6) \xi^{2}+2(1-\varepsilon)\right]}{2 \xi\left[\varepsilon\left(\xi^{3}-1\right)+1\right]}
\end{aligned}
$$

In this case, considering the absolute value of the terms constituting the friction force and the fact that the friction force is a dependent function of three independent variables, it needs to determine the sign of $\left(\Lambda_{\mathrm{F}}\right)_{\mathrm{I}}$ and $\left(\Lambda_{\mathrm{F}}\right)_{\mathrm{II}}$ for different ranges of variations of independent variables. Examination of equations (28-1) and (28-2) based on the variations of $\Lambda$ shows that the behaviour of $\Lambda_{\mathrm{F}}^{\prime}$ could be analysed in three different ranges for $\Lambda$ :

i) $\quad$ For $\Lambda<0$, in general, the minimum of $\Lambda_{\mathrm{F}}^{\prime}$ takes place for base length ratios calculated from equation (25) for any given $\Lambda$ and $\xi$ and the global minimum for any given $\Lambda$ happens when $\xi \rightarrow \infty$ which results in $\left(\Lambda_{\mathrm{F}}^{\prime}\right)_{\min }=|\Lambda / 2|$.

ii) In the range of $0<\Lambda<2$, for any given $\xi$, the minimum of $\Lambda_{\mathrm{F}}^{\prime}$ occurs either when

$$
\left(\varepsilon_{o p t}\right)_{F^{\prime}}=\varepsilon_{1}=\frac{\Lambda \xi^{3}+6 \xi-8}{2\left(\xi^{3}+3 \xi-4\right)}
$$

or

$$
\left(\varepsilon_{\text {opt }}\right)_{F^{\prime}}=\varepsilon_{2}=\frac{\Lambda \xi^{2}-2}{2\left(4 \xi^{3}-3 \xi^{2}-1\right)}
$$

which dependent to the value of $\Lambda$ one of them would be global and the other local minimum point for the given height ratio. However, considering the limits of variations of height and base length ratios, the global minimum for friction force happens when $\varepsilon \rightarrow 0$ and $\xi=(2 / \Lambda)^{1 / 2}$ or $\xi \rightarrow \infty$ and $\varepsilon^{=} \varepsilon_{2}$ (resulting in $\varepsilon=\Lambda / 2$ ) both which offer $\left(\Lambda_{\mathrm{F}}^{\prime}\right)_{\min }=0$.

iii) For $\Lambda \geq 2$, the minimum of $\Lambda_{\mathrm{F}}^{\prime}$ happens either $\varepsilon \rightarrow 1$ for all $\xi$ or $\xi \rightarrow 1$ for all $\varepsilon$ both resulting in $\left(\Lambda_{\mathrm{F}}^{\prime}\right)_{\min }=|1-\Lambda / 2|$. In addition, $\varepsilon=\varepsilon_{2}$ provides the local minimum $\Lambda_{\mathrm{F}}^{\prime}$ for any given $\xi$.

Figure 4 demonstrates variations of $\Lambda_{\mathrm{F}}^{\prime}$ with height ratio for some different $\Lambda$ when $\varepsilon=0.35$. Comparing Figures 3 and 4 indicates that for $\Lambda \leq 0$, the trend of the results is the same, whilst for $\Lambda>0$ the results change considerably. It should be noted that the results in Figure 4 are also scaled between 0 and 1 for better representation.

\subsection{The friction coefficient}

Based on what definition for friction force introduced in the previous section is intended, the modified friction coefficient can be calculated from equation (22). If the friction coefficient is calculated as an absolute value of dimensionless friction force given in equation (18), the minimum friction coefficient for $0<\Lambda<2$ would happen when $\Lambda_{\mathrm{F}}=0$. In the ranges of $-0.295<\Lambda<0$ (considering the limitations to have possible positive load 
Tribology International, 2009, Vol. 42, No. 5, pp. 666-674

(Accepted Version)

capacity) and $\Lambda>2$, the minimum friction coefficient would happen if the set of equations below were solved for $\varepsilon$ and $\xi$ :

$$
\left\{\begin{array}{l}
\left(\xi_{\text {opt }}\right)_{\eta}=\frac{1}{12 \varepsilon}\left[\left(A_{1}+12 \varepsilon \sqrt{6(1-\varepsilon) A_{2}}\right)^{1 / 3}+(\Lambda+6 \varepsilon)^{2}\left(A_{1}+12 \varepsilon \sqrt{6(1-\varepsilon) A_{2}}\right)^{-1 / 3}+(\Lambda+6 \varepsilon)\right] \\
\left(\varepsilon_{\text {opt }}\right)_{\eta}=\frac{-B_{1} \pm \xi^{2} \sqrt{\left(\Lambda \xi^{2}+\Lambda \xi+\Lambda+6\right) B_{2}}}{(\xi-1) B_{3}}
\end{array}\right.
$$

in which

$$
\begin{aligned}
& A_{1}=(\Lambda+6 \varepsilon)^{3}+432 \varepsilon^{2}(1-\varepsilon) \\
& A_{2}=(\Lambda+6 \varepsilon)^{3}+216 \varepsilon^{2}(1-\varepsilon)
\end{aligned}
$$

and

$$
\begin{gathered}
B_{1}=\left(\xi^{2}+\xi+1\right) \xi^{2} \Lambda^{2}-2(\xi-1)(\xi-4) \xi \Lambda-12 \\
B_{2}=(2 \xi+1) \xi^{3} \Lambda^{3}-2\left(4 \xi^{2}-6 \xi+5\right) \xi^{2} \Lambda^{2}-4(4 \xi-1) \xi \Lambda+24 \\
B_{3}=(\xi+1)\left(\xi^{2}+\xi+1\right) \xi^{2} \Lambda^{2}-2\left(2 \xi^{4}+\xi^{2}-\xi+4\right) \xi \Lambda-12(\xi+1)\left(\xi^{2}+1\right)
\end{gathered}
$$

The positive sign in $\left(\varepsilon_{\mathrm{opt}}\right)_{\eta}$ is for the range of $\Lambda>2$ and the negative sign is for the range of $-0.295<\Lambda<0$. It should be noted that for $2<\Lambda<8$ the set of equations in (30) provides a unique optimum point based on length and height ratios; offering the minimum friction coefficient for any $\Lambda$ in this range.

Figures 5 and 6 show the variations of minimum modified friction coefficient with base length ratio for some different modified bearing in the ranges of $-0.295<\Lambda \leq 0$ and $2<\Lambda \leq 8$ respectively. For the range of $\Lambda>8$, the minimum friction coefficient can be achieved when $\varepsilon \rightarrow 0$ and $\xi \rightarrow \infty$ which would be $\left(\eta_{\mathrm{M}}\right)_{\min }=1 / 2$.

Alternatively, if the (modified) friction coefficient is calculated based on friction force stated in equation (28), which will be demonstrated in the form of $\eta_{\mathrm{M}}^{\prime}$, the optimum cases for different ranges of $\Lambda$ can be summarised as below:

i) $\quad$ For $\Lambda<0$, the minimum of $\eta^{\prime}$ M mainly happens at height and base length ratios resulted from solving the set of equations in (30).

ii) In the range of $0<\Lambda<2$, for any given $\xi$, the minimum of $\eta^{\prime}$ M takes place either when $\varepsilon=\varepsilon_{1}$ or $\varepsilon=\varepsilon_{2}$ (considering equations 29-1 and 29-2), which dependent to the value of $\Lambda$, one of these base length ratios would be the global and the other local minimum point for any given height ratio.

However, considering the limits of variations of the height and base length ratios, the global minimum for friction coefficient happens when $\varepsilon \rightarrow 0$ and $\xi=(2 / \Lambda)^{1 / 2}$ or $\xi \rightarrow \infty$ and $\varepsilon=\varepsilon_{2}$ (resulting in $\varepsilon=\Lambda / 2$ ), both which offer $\left(\eta^{\prime}\right)_{\min }=0$.

iii) For $\Lambda=2$, the minimum of friction coefficient occurs when $\varepsilon \rightarrow 1$ for all $\xi$ or $\xi \rightarrow 1$ for all $\varepsilon$ both resulting in $\left(\eta^{\prime}{ }_{\mathrm{M}}\right)_{\min }=0$. In addition, $\varepsilon=\varepsilon_{2}$ provides the local minimum friction coefficient for any given $\xi$.

iv) In the range of $2<\Lambda<4.8$, the minimum of $\eta^{\prime}{ }_{M}$ happens when $\varepsilon=\varepsilon_{2}$ and for the height ratio resulting from solving the equation below:

$$
\left.\frac{\partial\left(\eta_{\mathrm{M}}^{\prime}\right)}{\partial \xi}\right|_{\varepsilon=\varepsilon_{2}}=0
$$

v) For $\Lambda>4.8$, the minimum of $\eta^{\prime}{ }_{M}$ happens when $\varepsilon=\varepsilon_{2}$ and $\xi \rightarrow \infty$, which results in $\left(\eta^{\prime} \mathrm{M}\right)_{\min }=1 / 2$. 
Tribology International, 2009, Vol. 42, No. 5, pp. 666-674

(Accepted Version)

\subsection{The volume flow rate of lubricant}

Examining of the first derivative of the lubricant flow rate with respect to base length ratio, $\varepsilon$ shows no specific critical point. Nevertheless, calculating of the first derivative of the lubricant flow rate with respect to height ratio, $\xi$ results in a critical point as follow:

$$
\left(\xi_{\text {ext }}\right)_{q}=\frac{1}{12 \varepsilon}\left[\left(A_{1}+12 \varepsilon \sqrt{6(1-\varepsilon) A_{2}}\right)^{1 / 3}+(6 \varepsilon-\Lambda)^{2}\left(A_{1}+12 \varepsilon \sqrt{6(1-\varepsilon) A_{2}}\right)^{-1 / 3}+(6 \varepsilon-\Lambda)\right]
$$

in which $\Lambda<2$ and,

$$
\begin{aligned}
& A_{1}=-(\Lambda-6 \varepsilon)^{3}+432 \varepsilon^{2}(1-\varepsilon) \\
& A_{2}=-(\Lambda-6 \varepsilon)^{3}+216 \varepsilon^{2}(1-\varepsilon)
\end{aligned}
$$

For the range of $\Lambda>2$, there is not any specific result as critical height ratio considering the range of variations of height ratio, in general. It is also noted that for the modified bearing number in the range of ]0,2], to have a real value for critical height ratio, it needs that the following condition in the equation (32) holds,

$$
6(1-\varepsilon) A_{2}>0
$$

Examining the second derivative of the flow rate with respect to height ratio shows that for the resulted extremum points, the second derivative is negative denoting that the obtained points are the locus of maximum volume flow rate since the flow rate has positive values for the these points. In fact, equation (32) is the location of points that should be avoided as they provide maximum lubricant flow rate.

Variations of $\left(\xi_{\text {ext }}\right)_{\mathrm{q}}$ with base length ratio for some different modified bearing numbers $(\Lambda<2)$ are shown in Figure 7 . As can be seen through this figure, the critical height ratio increases as the base length ratio and modified bearing number both reduce. In addition, Figure 8 shows the variations of maximum volume flow rate of lubricant with base length ratio for some different modified bearing numbers $(\Lambda<2)$. Variations of maximum flow rate with both base length ratio and modified bearing number is in line with the variations of the critical height ratio with those parameters.

\subsection{The special case of $\Delta p=0$}

When there is no pressure difference between two ends of the bearing, the load capacity of the bearing is entirely supported by the hydrodynamic pressure distribution inside the bearing and the hydrostatic pressure support no longer exists. This would result in $\Lambda=0$, reducing equations to a simpler form, which are usually considered in textbooks (e.g. see [3]) when the Rayleigh step bearing is introduced. Due to its central importance, the optimum parameters for Rayleigh step will be examined here based on different objective functions. As is already known through the literature (e.g. see the same reference above), the minimum load capacity is $\left(\Lambda_{\mathrm{W}}\right)_{\mathrm{min}} \approx 0.2063$ which happens when $\xi \approx 1.866$ and $\varepsilon \approx 0.2818$.

The profile of optimum Rayleigh step bearing and corresponding pressure distribution that is calculated from equation (6) are shown in Figure 9. In this figure, the bearing height is nondimensionalised based on the minimum clearance, $h_{1}$ and the $x$ coordinate is nondimensionalised based on the total bearing length, $L$. The pressure is also in dimensionless form calculated as below 
Tribology International, 2009, Vol. 42, No. 5, pp. 666-674

(Accepted Version)

$$
p^{*}=\frac{\left(p-P_{0}\right) h_{1}{ }^{2}}{\mu U L}
$$

Considering the dimensionless friction force in equation (18), one may seen that for $\Lambda=0$ the height ratios given by equation (26) for any base length ratio would be the location of inflexion points. In addition, the minimum of friction force happens when $\xi \rightarrow \infty$ and $\varepsilon \rightarrow 0$, whilst for $\xi \rightarrow 1$ and/or $\varepsilon \rightarrow 1$ the maximum friction force $\left(\Lambda_{\mathrm{F}}=1\right)$ happens.

If the friction force is considered based on equation (28), which comprises the entropy concept, the behaviour of the friction force at the limits remains almost similar to the behaviour of previous form of friction force. In this case it is also possible to introduce a local maximum point which happens when $\xi \approx 2.225$ and $\varepsilon \approx 0.1223$. Consequently, at this point, the dimensionless friction force would be $\Lambda_{F}^{\prime}=0.844$.

The friction coefficient has a global minimum point as it could be predicted from the behaviour of the load capacity and friction force functions. The minimum dimensionless modified friction coefficient is $\left(\eta_{\mathrm{M}}\right)_{\min }=4$, which happens when $\xi=2$ and $\varepsilon=1 / 5$. At this point, the dimensionless load capacity and friction force are $\Lambda_{\mathrm{W}}=1 / 5$ and $\Lambda_{\mathrm{F}}=4 / 5$ respectively. Considering friction coefficient based on the entropy generation minimising concept, it can be shown that the same point will provide the minimum friction coefficient.

Since the lubricant flow rate has no extremum point(s) based on base length ratio, according to equation (32) it is possible to introduce the critical height ratio corresponding to any given base length ratio. It also might be of interest to examine the ratio of dimensionless load capacity to lubricant flow rate $\left(\Lambda_{\mathrm{W}} / \Lambda_{\mathrm{q}}\right)$ in order to find any possible optimum situation(s) for this case. Examining the resulted equation following the same procedure employed in this study so far, shows that such a point exists at $\xi \approx 1.78078$ and $\varepsilon \approx 0.3596$ in which the ratio of dimensionless load capacity to dimensionless lubricant flow rate is the maximum value. At this point, the corresponding values of dimensionless load capacity, lubricant flow rate and $\Lambda_{\mathrm{W}} / \Lambda_{\mathrm{q}}$ are $0.2019,0.5936$ and 0.3402 respectively.

\section{Conclusions}

In the present part of study, the Rayleigh step bearing was examined analytically and rather extensively by considering the variations of hydrostatic pressure at the bearing ends in order to find the circumstances in which the optimum Rayleigh step can be introduced concerning load capacity and friction force, friction coefficient and lubricant flow rate. The corresponding relations for load capacity, friction force and lubricant flow rate of an infinite width Rayleigh step bearing are introduced by providing an analytical solution to $1 \mathrm{D} / 2 \mathrm{D}$ form of the Reynolds lubrication equation. Then, by introducing dimensionless geometrical parameters, a series of dimensionless analytical relations for the bearing performance parameters are introduced. The resulted relations made it possible to search for the potential optimum parameters for Rayleigh step considering the variations in pressure difference between two ends of the bearing.

It was shown that the optimum step geometry in terms of base length ratio and height ratio is dependent to the variations of pressure at the bearing boundaries. In some ranges of variations of the bearing number, it might not be possible to introduce a global optimum point. It was observed that the optimum geometry offering minimum friction force in most of the cases happens at the boundaries of the variable parameters. It was 
Tribology International, 2009, Vol. 42, No. 5, pp. 666-674

(Accepted Version)

also discussed that the optimisation of friction force can be considered from two points of view: 1) reducing the net resistant force exerted on the bearing surface(s) or 2)

minimising the friction force in terms of minimising the entropy generation.

Consequently, analysis of friction coefficient can also be divided into two rather different categories based on what friction force is of interest. It was discussed that in these two cases the possible optimums can differ.

Finally, it was also pointed out that the location of optimum points based on friction coefficient can vary from those of load capacity, in general. Hence, the optimum height and base length ratio for minimising the friction coefficient were introduced for the case in which there is no pressure difference between bearing ending boundaries. The optimum parameters based on maximisation of the ratio of load capacity to lubricant flow rate was also introduced in order to achieve an optimum condition in which the load capacity is the maximum whilst the lubricant consumption is considered.

\section{Nomenclature}

$\begin{array}{ll}A_{1}, A_{2} & \text { intermediate variables } \\ a & \text { coordinate of bearing leading edge } \\ B_{1}, B_{2}, B_{3} & \text { intermediate variables } \\ b & \text { step coordinate } \\ c & \text { coordinate of bearing trailing edge } \\ c_{1}, \mathrm{C}_{2} & \text { integration constants } \\ F & \text { friction force } \\ h & \text { surface profile } \\ h_{1} & \text { height of non-stepped part } \\ h_{2} & \text { height of step } \\ l_{1} & \text { length of non-stepped part } \\ l_{2} & \text { length of step } \\ p_{*} & \text { pressure } \\ p^{*} & \text { dimensionless pressure } \\ P_{0} & \text { ambient pressure } \\ P_{a} & \text { pressure at the leading edge } \\ P_{b} & \text { pressure at the trailing edge } \\ q & \text { volume flow rate of lubricant } \\ u & \text { velocity profile } \\ U & \text { velocity } \\ U_{1} & \text { bearing (lower surface) velocity } \\ W & \text { bearing load capacity } \\ x & x \text {-coordinates } \\ y & y \text {-coordinates }\end{array}$

Greek symbols

$\Delta p \quad$ pressure difference

$\varepsilon \quad$ base length ratio

$\eta \quad$ friction coefficient

$\eta_{\mathrm{M}} \quad$ modified friction coefficient

$\eta_{\mathrm{M}}^{\prime} \quad$ modified friction coefficient considering entropy

$\Lambda \quad$ modified bearing number 
Tribology International, 2009, Vol. 42, No. 5, pp. 666-674

(Accepted Version)

$\begin{array}{ll}\Lambda_{\mathrm{F}} & \text { dimensionless friction force (net resistance force) } \\ \Lambda_{\mathrm{F}}^{\prime} & \text { dimensionless friction force considering entropy } \\ \Lambda_{\mathrm{q}} & \text { dimensionless lubricant flow rate } \\ \Lambda_{\mathrm{W}} & \text { dimensionless load capacity } \\ \mu & \text { dynamic viscosity } \\ \xi & \text { step height ratio } \\ \tau & \text { shear stress } \\ & \text { Subscripts } \\ \text { I } & \text { related to region I of the bearing (non-stepped part) } \\ \text { II } & \text { related to region II of the bearing (stepped part) } \\ \text { ext } & \text { extremum (critical) point or value } \\ \mathrm{F} & \text { based on friction force } \\ \min & \text { minimum } \\ \text { max } & \text { maximum } \\ \text { opt } & \text { optimum } \\ \mathrm{q} & \text { based on lubricant flow rate } \\ \mathrm{W} & \text { based on load capacity } \\ \eta & \text { based on friction coefficient }\end{array}$

\section{Abbreviations}

$1 \mathrm{D}$

one-dimensional

two-dimensional

$\begin{array}{ll} & \text { Mathematical symbols } \\ \approx & \text { intends to (aims at) } \\ \infty & \text { approximately equal } \\ \mid \infty & \text { infinity } \\ || & \text { absolute value } \\ ],] & \text { half-closed range from right hand side } \\ {[,]} & \text { closed range }\end{array}$

\section{References}

1. Stachowiak G.W., Batchelor A.W., Engineering tribology, $2^{\text {nd }}$ Ed., Butterworth Heinemann, US, 2001

2. Cameron A., Basic lubrication theory, Longman Group Ltd., GB, 1971

3. Pinkus O., Strenlicht B., Theory of hydrodynamic lubrication, McGraw-Hill Inc., US, 1961

4. Archibald F.R., A simple hydrodynamic thrust bearing, ASME Trans. 1950, 72(4): 393-400

5. Archibald F.R., The stepped shape film applied to a journal bearing, Franklin Inst. 1952, 253(1): 21-28

6. Hamrock B.J., Anderson W.J., Rayleigh step journal bearing. Part II - Incompressible fluid, J. Lubr. Tech., ASME Trans. 1969, 91(4): 641-650

7. Hamrock B.J., Anderson W.J., Incompressibly lubricated Rayleigh step journal bearing. I -Zero-order perturbation solution, NASA TN D-4839, Oct. 1968 
Tribology International, 2009, Vol. 42, No. 5, pp. 666-674

(Accepted Version)

8. Hamrock B.J., Anderson W.J., Incompressibly lubricated Rayleigh step journal bearing. II -Infinite-length solution, NASA TN D-4873, Nov. 1968

9. Schuller F.T., Experiments on the stability of water-lubricated Rayleigh step hydrodynamic journal bearings at zero load, NASA TN D-6514, Sep. 1971

10. Auloge J.Y., Bourgin P., Gay B., The optimum design of one-dimensional bearings with non-Newtonian lubricants, J. Lubr. Tech., ASME Trans. 1983, 105: 391-395

11. Jianming W., Gaobing J., The optimal design of the Rayleigh slider bearings with a power law fluid, Wear 1989, 129: pp. 1-11

12. Tello J.I., Regularity of solutions to a lubrication problem with discontinuous separation data, Nonlinear Analysis. 2003, 53: 1167-1177

13. Zhu X., Experimental response of a rotor supported on Rayleigh step gas bearings, Master Thesis, Aug. 2004, Texas A\&M University, TX, US

14. Hideki O., Thermohydrodynamic lubrication analysis method of step bearings, IHI Eng. Rev. 2005, 38(1): 6-10

15. Farmer D.G., Shepherd J.J., Slip flow in the gas-lubricated Rayleigh step-slider bearing, Int. J. App. Mech. \& Eng. 2006, 11(3): 593-608

16. Naduvinamani N.B., Siddangouda A., Effect of surface roughness on the hydrodynamic lubrication of porous step-slider bearings with couple stress fluids, Tribology Int. 2007, 40: 780-793

17. Halling J., Principles of tribology, The Macmillan Press Ltd., HK, 1978

\section{Figure Captions}

Figure 1. The Rayleigh step bearing

Figure 2. Variations of the maximum load capacity based on base length ratio versus step height ratios for different modified bearing numbers. The global maximum load capacities (considering both height and base length ratios) are shown for $-0.295<\Lambda<1.095$ as well as the correspondent value of optimum base length ratios

Figure 3. Variations of absolute value of scaled friction force with step height ratio for different modified bearing numbers when $\varepsilon=0.35$

Figure 4. Variations of the scaled friction force (calculated based on minimisation of entropy generation concept) between 0 and 1 with step height ratio for different modified bearing numbers when $\varepsilon=0.35$

Figure 5. Variations of the modified friction coefficient with base length ratios for different modified bearing numbers in the range of $-0.295<\Lambda \leq 0$. The locations of the global minimum points (considering correspondent height ratios) are also demonstrated Figure 6. Variations of the modified friction coefficient with base length ratio for different modified bearing numbers in the range of $2<\Lambda \leq 8$. The locations of the global minimum points (considering correspondent height ratios) are also demonstrated Figure 7. Variations of the critical height ratio with base length ratios for different modified bearing numbers when $\Lambda<2$

Figure 8. Variations of the dimensionless maximum lubricant flow rate with base length ratio for different modified bearing numbers when $\Lambda<2$

\section{Figures}


Tribology International, 2009, Vol. 42, No. 5, pp. 666-674

(Accepted Version)

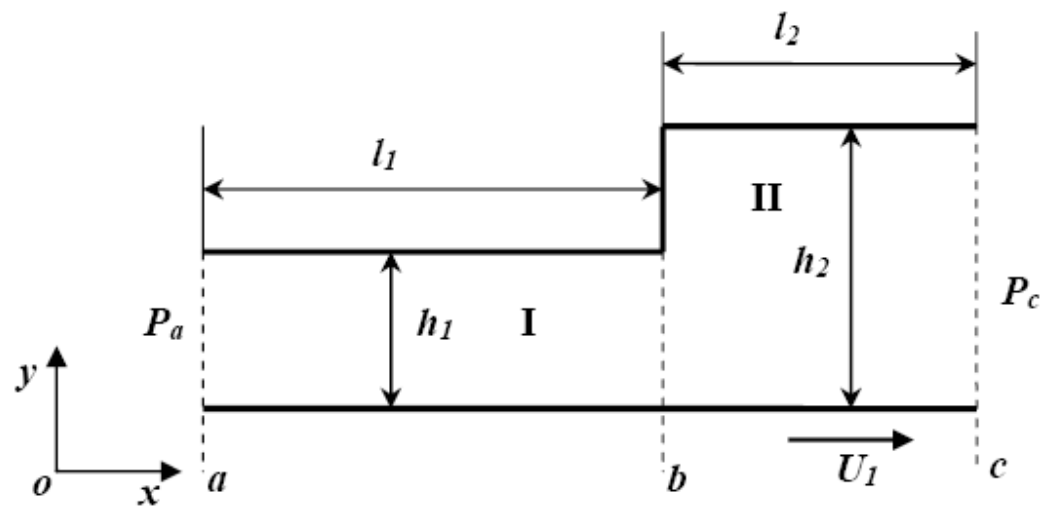

Figure 1. The Rayleigh step bearing 
Tribology International, 2009, Vol. 42, No. 5, pp. 666-674

(Accepted Version)

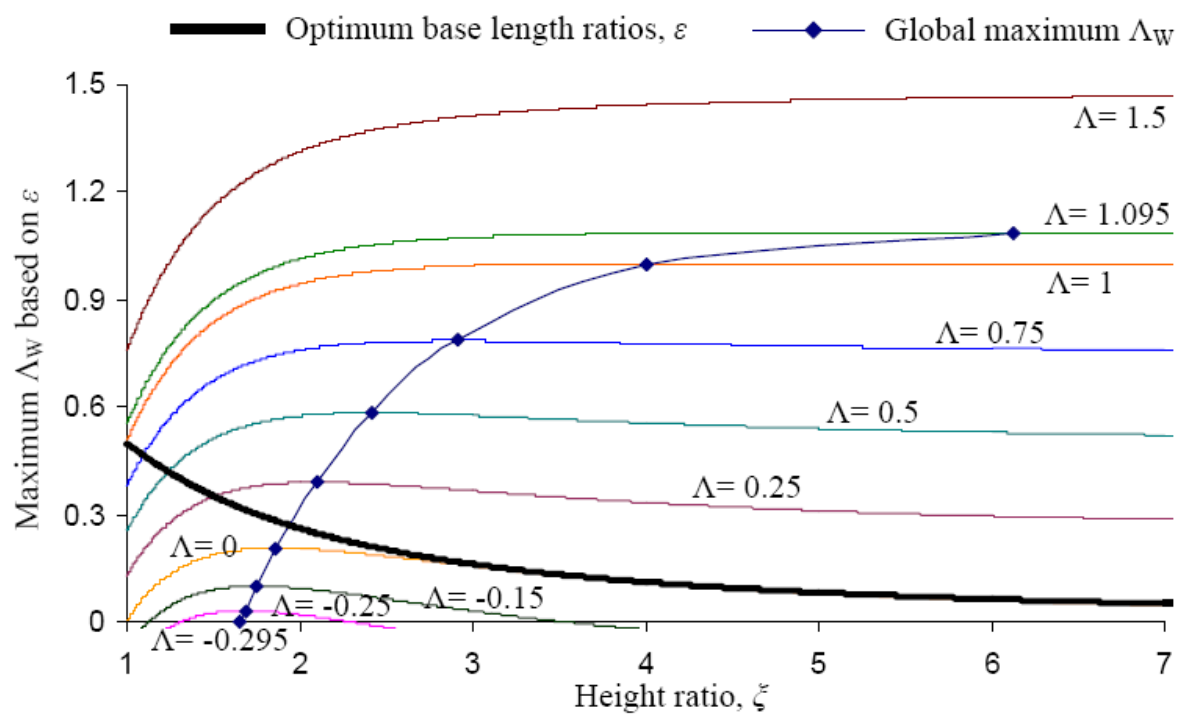

Figure 2. Variations of the maximum load capacity based on base length ratio versus step height ratios for different modified bearing numbers. The global maximum load capacities (considering both height and base length ratios) are shown for $-0.295<\Lambda<1.095$ as well as the correspondent value of optimum base length ratios 
Tribology International, 2009, Vol. 42, No. 5, pp. 666-674

(Accepted Version)

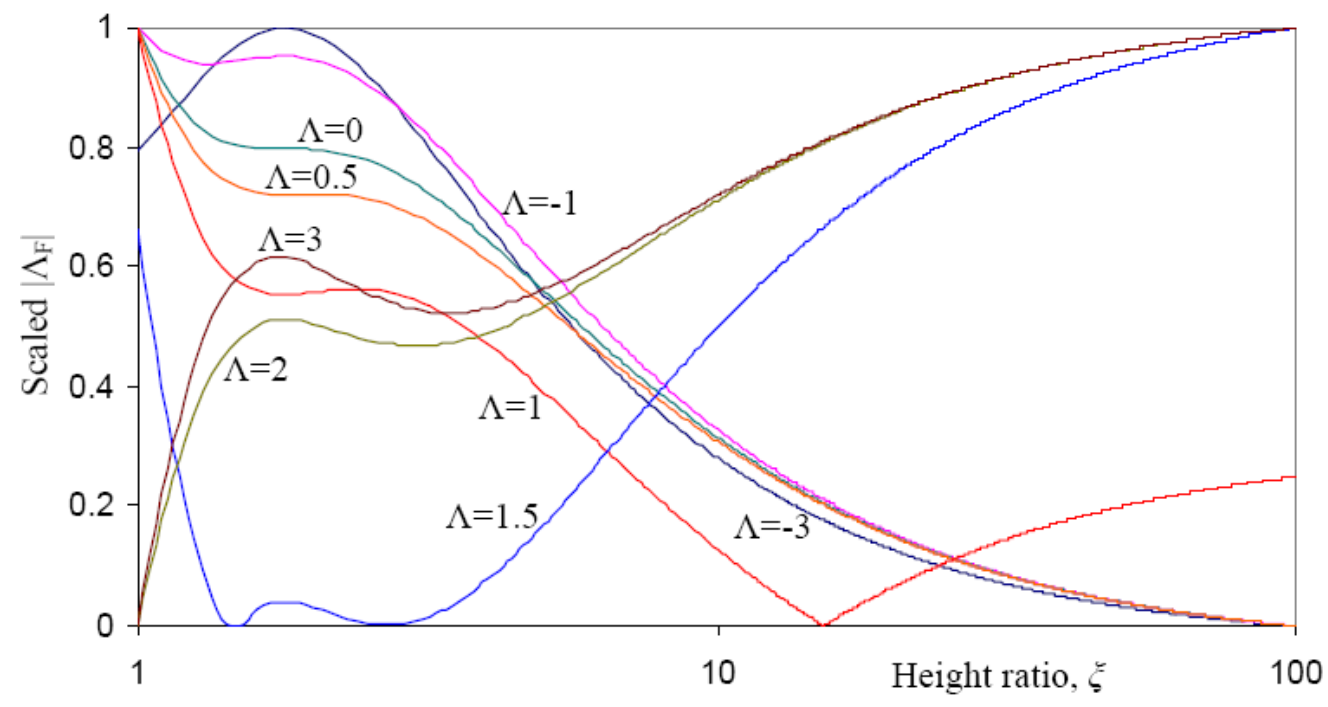

Figure 3. Variations of absolute value of scaled friction force with step height ratio for different modified bearing numbers when $\varepsilon=0.35$ 
Tribology International, 2009, Vol. 42, No. 5, pp. 666-674

(Accepted Version)

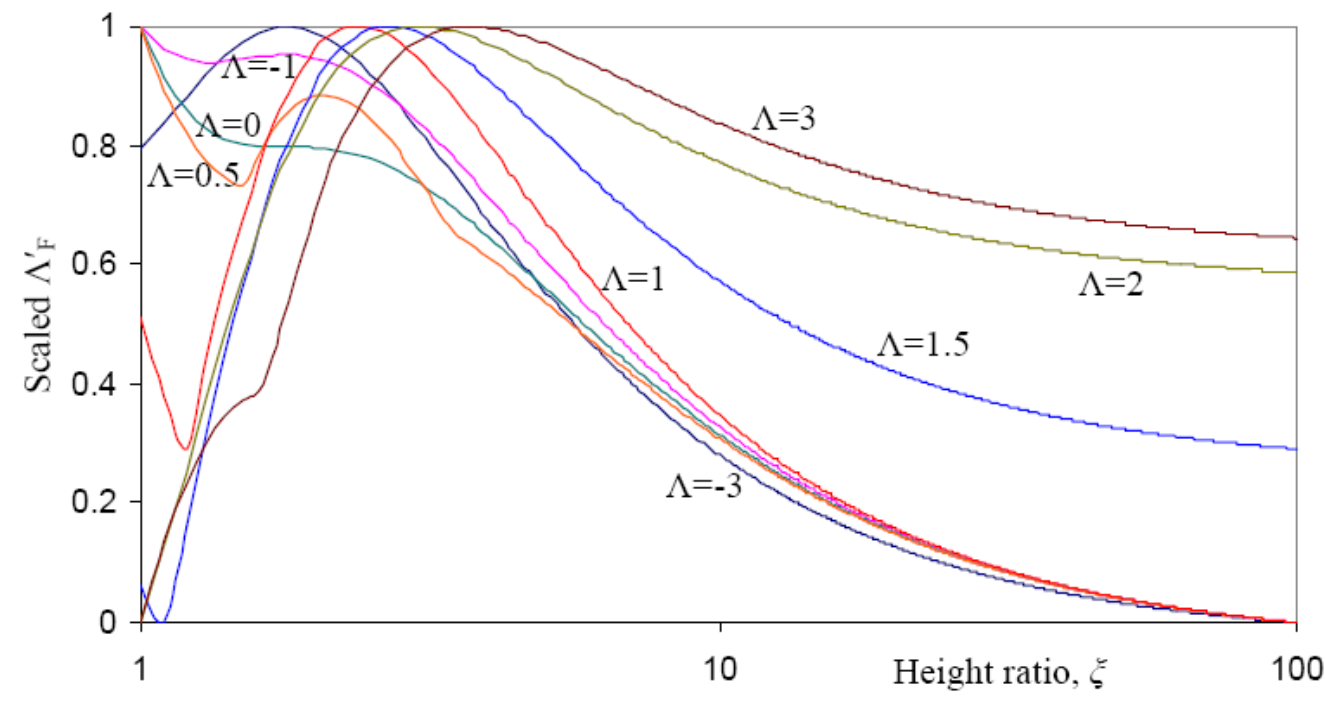

Figure 4. Variations of the scaled friction force (calculated based on minimisation of entropy generation concept) between 0 and 1 with step height ratio for different modified bearing numbers when $\varepsilon=0.35$ 
Tribology International, 2009, Vol. 42, No. 5, pp. 666-674

(Accepted Version)

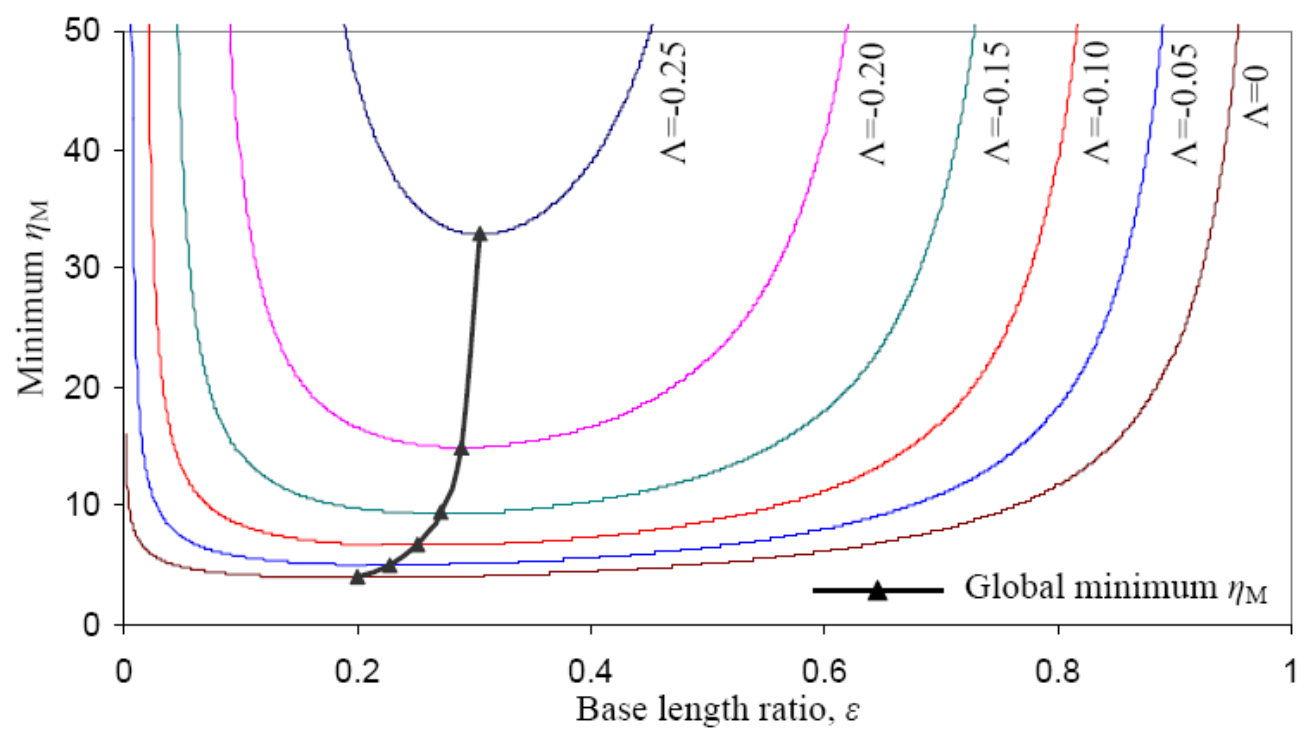

Figure 5. Variations of the modified friction coefficient with base length ratios for different modified bearing numbers in the range of $-0.295<\Lambda \leq 0$. The locations of the global minimum points (considering correspondent height ratios) are also demonstrated 
Tribology International, 2009, Vol. 42, No. 5, pp. 666-674

(Accepted Version)

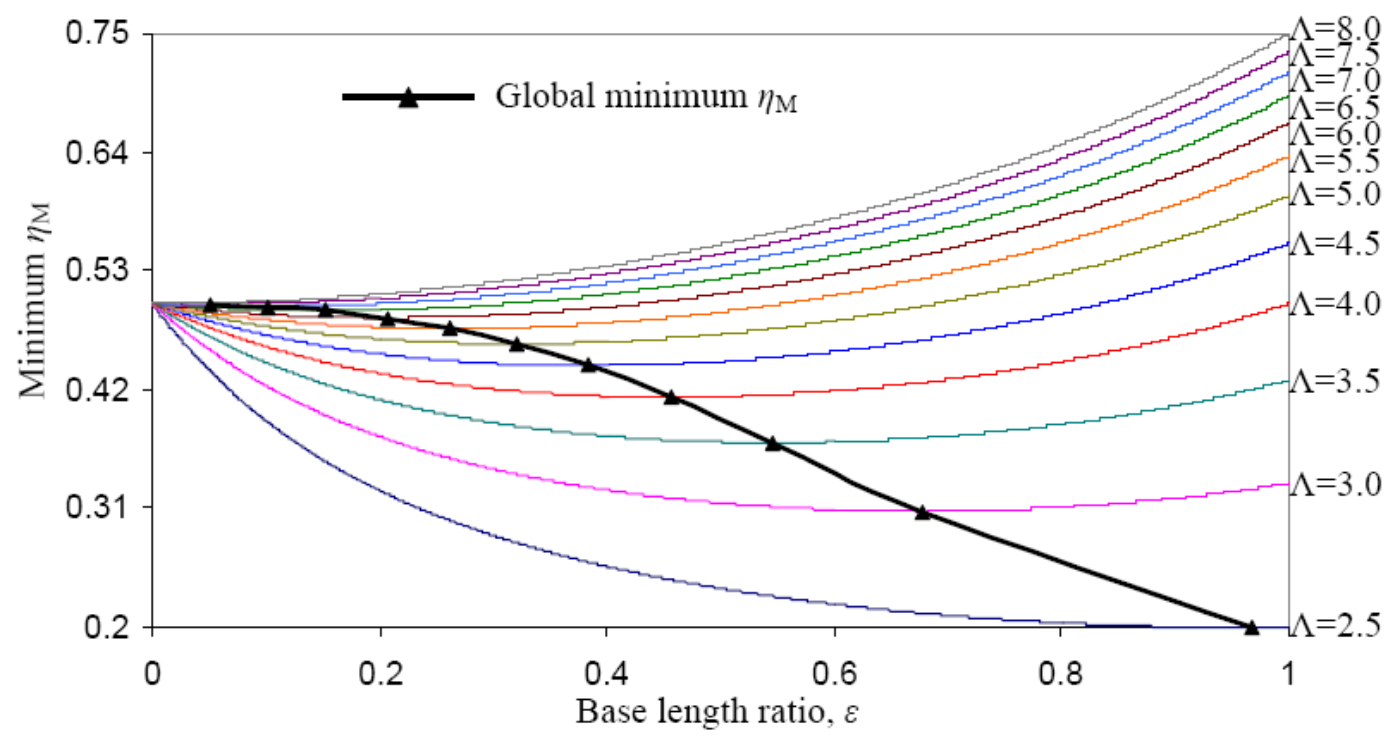

Figure 6. Variations of the modified friction coefficient with base length ratio for different modified bearing numbers in the range of $2<\Lambda \leq 8$. The locations of the global minimum points (considering correspondent height ratios) are also demonstrated 
Tribology International, 2009, Vol. 42, No. 5, pp. 666-674

(Accepted Version)

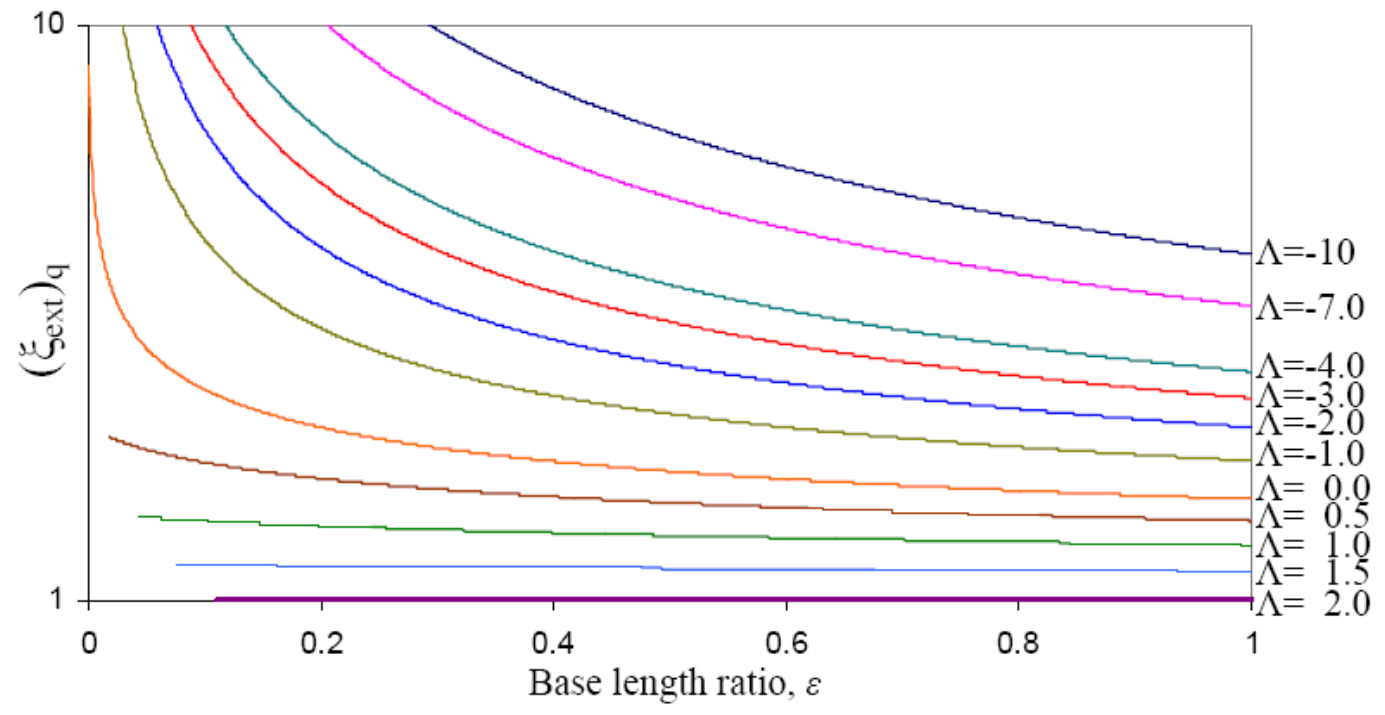

Figure 7. Variations of the critical height ratio with base length ratios for different modified bearing numbers when $\Lambda<2$ 
Tribology International, 2009, Vol. 42, No. 5, pp. 666-674

(Accepted Version)

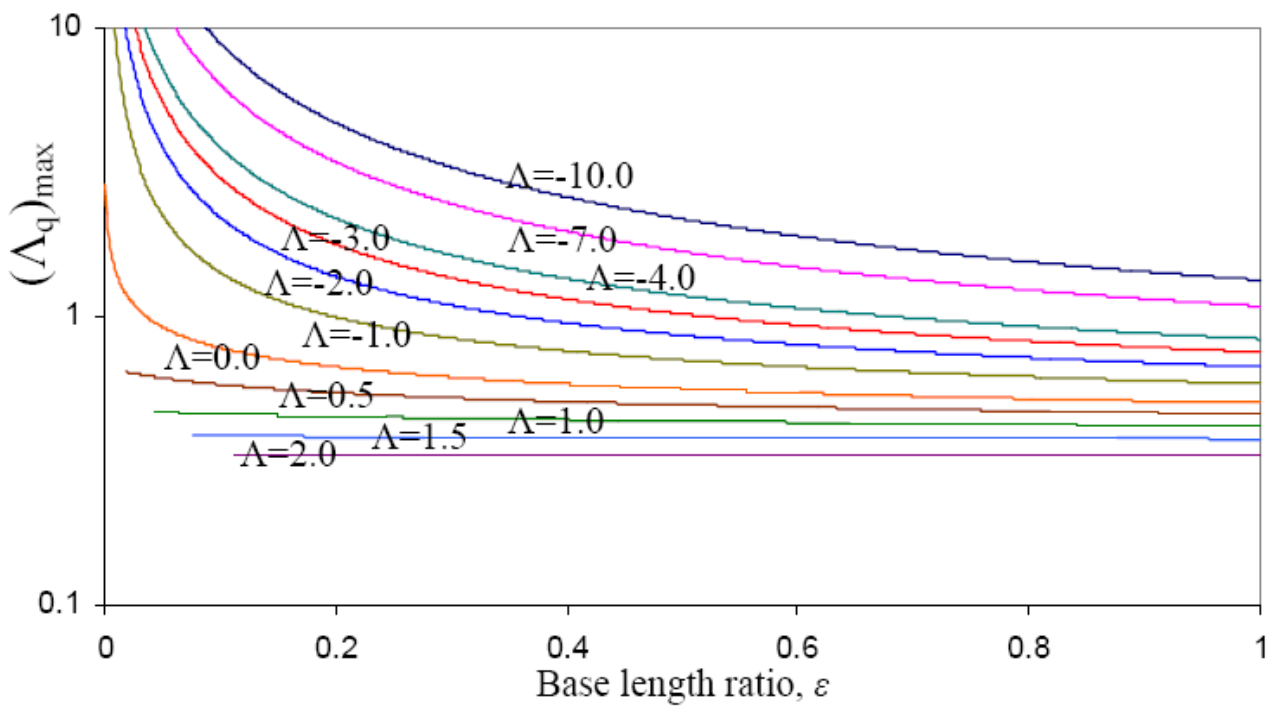

Figure 8. Variations of the dimensionless maximum lubricant flow rate with base length ratio for different modified bearing numbers when $\Lambda<2$ 